九州大学学術情報リポジトリ

Kyushu University Institutional Repository

\title{
Receptor-binding cancer antigen expressed on SiSo cells induces apoptosis via ectodomain shedding
}

Sonoda, Kenzo

Department of Obstetrics and Gynecology, Graduate School of Medical Sciences, Kyushu University

Miyamoto, Shingo

Department of Obstetrics and Gynecology, Faculty of Medicine, Fukuoka University

Nakashima, Manabu

Department of Clinical Pharmacology, Faculty of Pharmaceutical Sciences, Fukuoka University

Wake, Norio

Department of Obstetrics and Gynecology, Graduate School of Medical Sciences, Kyushu University

ht tp://hdl. hand le. net/2324/26060

出版情報: Experimental Cell Research. 316 (11)，pp.1795-1803，2010-07-01. Elsevier バージョン：

権利関係: (C) 2010 Elsevier Inc. 


\section{Receptor-binding cancer antigen expressed on SiSo cells induces apoptosis via ectodomain shedding}

Kenzo Sonoda ${ }^{1}$, Shingo Miyamoto ${ }^{2}$, Manabu Nakashima ${ }^{3}$, and Norio Wake $^{1}$

${ }^{1}$ Department of Obstetrics and Gynecology, Graduate School of Medical Sciences, Kyushu University, Fukuoka 812-8582, Japan; ${ }^{2}$ Department of Obstetrics and Gynecology, Faculty of Medicine, Fukuoka University, Fukuoka 814-0180, Japan; ${ }^{3}$ Department of Clinical Pharmacology, Faculty of Pharmaceutical Sciences, Fukuoka University, Fukuoka 814-0180, Japan

Corresponding author: Kenzo Sonoda, MD, PhD, Department of Obstetrics and Gynecology, Graduate School of Medical Sciences, Kyushu University, Maidashi 3-1-1, Higashi-ku, Fukuoka 812-8582, Japan.

Tel: 81-92-642-5395

Fax: 81-92-642-5414

E-mail: kenzo@med.kyushu-u.ac.jp 


\section{Abstract}

Receptor-binding cancer antigen expressed on SiSo cells (RCAS1) is a secreted antigen that induces apoptosis in putative receptor-expressing cells, including peripheral lymphocytes and natural killer (NK) cells. RCAS1 expression is associated with aggressive characteristics and poor overall survival for 15 different human malignancies. The putative RCAS1 receptor has not been isolated and the mechanism of RCAS1 apoptosis induction remains unclear. This study explores how RCAS1 is involved in apoptosis initiation. The cell lines SiSo and MCF-7, human uterine carcinoma and breast adenocarcinoma, respectively, both express RCAS1, but RCAS1 secretion is undetectable in MCF-7 cells. SiSo and MCF-7 cells were stimulated to induce RCAS1 ectodomain shedding followed by assessment of RCAS1 expression and secretion. Additionally, the RCAS1 putative receptor-expressing human chronic myelogenous leukemia cell line K562 was co-cultured with SiSo, MCF-7, or soluble RCAS1 to follow RCAS1 secretion in apoptosis initiation. RCAS1 secretion was strongly suppressed by inhibitors of metalloproteases, protein kinase $\mathrm{C}(\mathrm{PKC})-\delta$, mitogen-activated protein kinase (MAPK)/extracellular signal-regulated kinase kinase (MEK), epidermal growth factor (EGF), and G-protein-coupled receptor (GPCR). K562 apoptosis could be induced only by co-culturing with SiSo or soluble RCAS1. RCAS1 is thus secreted by ectodomain shedding, which may represent a pivotal step in RCAS1-induced apoptosis initiation.

Key words: RCAS1; ectodomain shedding; protease; apoptosis 


\section{Introduction}

RCAS1 is a prognostic factor for 15 different types of human cancer and its expression correlates with aggressive characteristics of cancer, such as clinical stage, histological subtype, differentiation, tumor size, depth of invasion, lymphovascular space involvement, lymph node metastasis, and peritoneal cytological results [1]. RCAS1 expression is increased in both pre-cancerous lesions and cancer of the uterine cervix and endometrium [2,3], suggesting that the expression and distribution of RCAS1 may be involved in malignant transformation and tumor progression in human cancers.

RCAS1 is a type II membrane protein that acts as a ligand for a putative receptor present in various human cell lines, and on normal peripheral lymphocytes and NK cells [4]. Addition of recombinant soluble RCAS1 inhibits the in vitro growth of these receptor-expressing cells and induces apoptosis. To date, more than 15 published immunohistochemical studies, using tissue samples collected from cancer patients, revealed that tumor RCAS1 expression is associated with an increased number of apoptotic lymphocytes or a decreased number of tumor-infiltrating lymphocytes [1]. Therefore, RCAS1 is believed to aid the escape of tumor cells from immune surveillance. Additionally, we reported that RCAS1 expression is significantly associated with matrix metalloproteinase-1 (MMP-1) and laminin-5 expression in cervical cancer [5]. We also showed that the number of cells expressing vimentin significantly decreases in relation to the RCAS1 expression level in cervical and ovarian cancer $[5,6]$. 
Moreover, enhanced RCAS1 expression in COS-7 cells following introduction of the RCAS1-encoding gene significantly promotes in vivo tumor growth via increased expression of vascular endothelial growth factor (VEGF) [7]. In cervical cancer, RCAS1 expression correlates significantly with VEGF expression and microvessel density (MVD). These findings suggest that RCAS1 may play a pivotal role in tumor progression by modifying the characteristics of connective tissue around tumor cells.

The human uterine cervical carcinoma cell line SiSo secretes RCAS1 and the amount of secreted RCAS1 increases when cells are cultured with $12-O$-tetradecanoylphorbol-13-acetate (TPA) [5]. PKC- $\delta$ is activated by TPA, followed by metalloprotease induction. This means that RCAS1 is secreted by proteolytic processing. This proteolytic processing, also referred to as 'ectodomain shedding', is observed for growth factors, growth factor receptors, cell-adhesion molecules, extracellular matrix proteins and other membrane proteins such as the $\beta$-amyloid precursor protein [8]. Ectodomain shedding affects the biological activity of membrane proteins by changing their fate, location and mode of action. In the case of membrane-anchored growth factors, ectodomain shedding can convert them into diffusible factors and greatly influence their functions [9]. The membrane-anchored form of Spitz, a TGF- $\alpha$-like molecule that is an EGFR ligand in Drosophila, is inactive but is activated following proteolytic cleavage to yield a soluble protein [10]. In contrast, membrane-anchored c-kit ligand [11] and ephrins [12] are fully functional 
whereas their soluble forms exhibit little or no biological activity. Thus, ectodomain shedding is an important regulatory step for the function of membrane proteins involved in cell-cell communication in development, cell differentiation and tissue maintenance.

Although RCAS1 induces apoptosis in its putative receptor-expressing cells, the mechanisms by which RCAS1 does so remain unclear because its putative receptor has not been isolated. In order to understand more clearly how RCAS1 initiates apoptosis, we examined the following: (1) the mechanism of RCAS1 ectodomain shedding, and (2) how induction of secreted and membranous types of RCAS1 is involved in apoptosis. 


\section{Materials and methods}

\section{Cell lines}

The human uterine cervical adenocarcinoma cell line SiSo [13], human breast adenocarcinoma cell line MCF-7 [14], and human chronic myelogenous leukemia cell line K562 [15] were maintained in RPMI 1640 medium supplemented with 100 units $/ \mathrm{mL}$ penicillin $\mathrm{G}, 100 \mu \mathrm{g} / \mathrm{mL}$ streptomycin, and 10\% fetal bovine serum (FBS) (ICN Biomedical, Irvine, $\mathrm{CA}$, USA) in a humidified incubator $\left(37^{\circ} \mathrm{C}, 5 \% \mathrm{CO}_{2}\right)$.

\section{Evaluation of RCAS1 expression by flow cytometry}

To evaluate RCAS1 expression, flow cytometric analysis was performed using the 22-1-1 antibody (MBL, Nagoya, Japan), which is an IgM monoclonal antibody recognizing human RCAS1. Briefly, SiSo and MCF-7 cells were harvested and incubated on ice for 45 minutes with 22-1-1 antibody. After washing, the cells were incubated on ice for 45 minutes with fluorescein isothiocyanate-conjugated goat anti-mouse IgM antibody (Pierce, Rockford, IL, USA). The cells were again washed, and flow cytometric analysis performed by means of FACScan (Becton Dickinson, San Jose, CA, USA). Mouse IgM (Zymed Laboratories, South San Francisco, CA, USA) was used as a negative control antibody.

\section{Enzyme-linked immunosorbent assay (ELISA)}

We measured RCAS1 concentrations in the cell culture supernatant, in triplicate, by means of an ELISA kit (MBL), according to the 
manufacturer's instructions. The RCAS1 ELISA kit was applied in earlier investigations of the clinical significance of RCAS1 in uterine and ovarian cancer $[16,17]$. The sensitivity of the RCAS 1 assay is $0.008 \mathrm{U} / \mathrm{mL}$.

\section{Shedding stimulation}

SiSo and MCF-7 cells $\left(5 \times 10^{5}\right)$ were seeded in a 6 well-plate and incubated at $37^{\circ} \mathrm{C}$ with $5 \% \mathrm{CO}_{2}$. On the next day, the cell culture medium was discarded, serum-free RPMI-1640 medium was added and the cells incubated for 12 hours. RCAS1 ectodomain shedding was then stimulated by exposure to either: $64 \mathrm{nM}$ TPA (Wako, Osaka, Japan); $4 \mathrm{ng} / \mathrm{ml}$

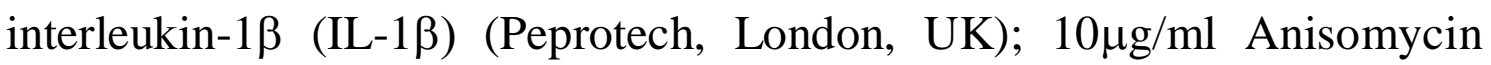

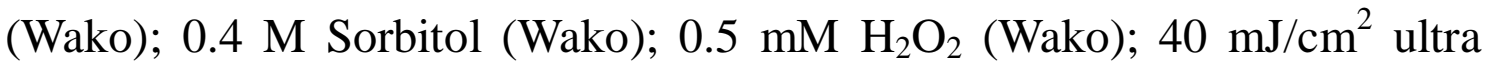
violet (UV) light: $100 \mathrm{nM}$ EGF (Wako); $0.2 \mu \mathrm{M}$ Endothelin (Wako); 2 U/ml Thrombin (Wako). Following the 60 minute incubation with stimuli, cells and culture supernatants were collected for further analysis. For trials that included inhibitors, shedding stimulation followed the inhibitor treatment. The cells were incubated for 60 minutes with inhibitors, which included: $5 \mu \mathrm{M}$ metalloprotease inhibitor GM6001 (Calbiochem, La Jolla, CA, USA); $25 \mu \mathrm{M}$ MEK inhibitor PD98059 (Wako); $10 \mu \mathrm{M}$ p38 MAPK (p38) inhibitor SB203580 (Wako); $25 \mu \mathrm{M}$ c-Jun N-terminal kinase (JNK) inhibitor SP600125 (Wako); $20 \mu$ M PKC inhibitor GF109203X (Wako); 20 $\mu \mathrm{M}$ protein kinase $\mathrm{B}$ (Akt) inhibitor IV (Calbiochem); $100 \mathrm{nM}$ EGF receptor (EGFR) inhibitor AG1478 (Wako); 10 $\mu \mathrm{M}$ GPCR inhibitor Cyclopamine V (Calbiochem). 


\section{Western blot analysis}

SiSo cells were lysed in radioimmunoprecipitation assay buffer [1\% Triton-X, $1 \%$ sodium deoxycholate, $0.1 \%$ sodium dodecyl sulfate (SDS), $150 \mathrm{mM} \mathrm{NaCl}, 50 \mathrm{mM}$ Tris (pH 8.0), 0.2 unit/mL aprotinin, $2 \mu \mathrm{g} / \mathrm{mL}$ leupeptin, $1 \mu \mathrm{g} / \mathrm{mL}$ pepstain A, $2 \mathrm{mM}$ phenylmethylsulfonyl fluoride, and 1 $\mathrm{mM}$ sodium orthovanadate]. Cell extracts were then subjected to SDS-polyacrylamide gel electrophoresis (PAGE) and immunoblotting analysis after transfer to Immobilon-P transfer membranes (Millipore Corporation, Bedford, MA, USA). Membranes were probed with several antibodies, including rabbit anti-phospho-PKC- $\delta$ (Cell Signaling Technology, Beverly, MA, USA), rabbit anti-PKC- $\delta$ (Sigma, St. Louis, MO, USA), mouse anti-phospho-extracellular signal regulated kinase (ERK)1/2 (Upstate, Lake Placid, NY, USA), rabbit anti-ERK1/2 (Santa Cruz, Santa Cruz, CA, USA), rabbit anti-phospho-JNK (Upstate), mouse anti-JNK (Santa Cruz), mouse anti-phospho-Akt (Cell Signaling Technology), or rabbit anti-Akt (Cell Signaling Technology) antibodies. Peroxidase-conjugated goat anti-rabbit (Southern Biotech, Birmingham, AL, USA) or anti-mouse (Chemicon, Temecula, CA, USA) IgG was used as secondary antibodies.

\section{Evaluation of apoptotic cell death}

Induction of apoptosis in K562 cells, which express the RCAS1 putative receptor, was evaluated by co-culturing with SiSo and MCF-7 as 
effector cells [1]. Then, $1 \times 10^{5}$ of each effector and K562 target cell were co-incubated in a 6 well-plate at 1-20:1 effector/target (E/T) ratio. In order to enhance tight cell-cell contact, the plates were centrifuged once after co-culture initiation. The suspended cells were harvested and stained with Annexin V-PE apoptosis detection kit (MBL) on days 1-4 after beginning the experiment. Flow cytometric analysis was performed to measure apoptotic cell number. In order to discriminate K562 cells from effector cells, K562 cells were stained by the Green fluorescence cell linker PKH kit (Sigma) before initiating the co-culture. K562 cells were also incubated with 1-10 U/mL of RCAS1, which was prepared from SiSo cell culture supernatant by ammonium sulfate precipitation. Flow cytometric analysis was also performed to assess apoptotic cell number after Annexin V-PE staining on days $1-4$.

\section{Statistical Analysis}

The Mann-Whitney test was performed to assess differences in RCAS1 expression and secretion, and the Annexin- $\mathrm{V}$ positive ratio between different cell groups. $P$ values of $<0.05$ were considered to be statistically significant. 


\section{Results}

\section{The expression and secretion of RCAS1 after shedding stimulation}

First, the expression and secretion of RCAS1 was evaluated. Flow cytometric analysis revealed that both SiSo and MCF-7 cells expressed RCAS1, although RCAS1 was barely detectable in MCF-7 culture supernatants (Fig. 1 and Fig. 2 A). RCAS1 expression and secretion was also undetectable in K562 cells alone (data not shown).

RCAS1 expression and secretion was analyzed in SiSo and MCF-7 cells after ectodomain shedding stimulation. The expression of RCAS1 at the surface of SiSo cells was drastically diminished after stimulation with TPA, IL-1 $\beta$, anisomycin, sorbitol, $\mathrm{H}_{2} \mathrm{O}_{2}$, UV, EGF, endothelin, and thrombin (Fig. 1 A). In contrast, RCAS1 expression levels in MCF-7 cells were not affected by shedding stimulation (Fig. 1 B).

The concentration of RCAS1 in the culture supernatant was measured by ELISA (Fig. 2 A). SiSo cells secreted RCAS1, which was increased in response to shedding stimulation $(P<0.05)$. MCF-7 cells did not secrete RCAS1 even after stimulation. RCAS1 secretion was assessed in SiSo cells cultured with several inhibitors (Fig. 2 B). GM6001 and GF109203X, metalloproteinase and PKC inhibitors, respectively, significantly suppressed RCAS1 secretion $(P<0.05)$; however, the MEK and p38 inhibitors PD98059 and SB203580, as well as the JNK inhibitor SP600125, and Akt inhibitor IV had little influence on RCAS1 secretion induced by TPA (Fig. 2 B (a)). Additionally, RCAS1 levels were assessed when inhibitors were added before EGF or GPCR ligand treatment (Fig. 2 
B (b) and (c)). EGFR, MEK, and JNK inhibitors (AG1478, PD98059, SP600125, respectively) and Akt inhibitor IV significantly suppressed RCAS1 secretion $(P<0.05)$; however, the p38 inhibitor SB203580 and PKC inhibitor GF109203X did not affect RCAS1 secretion caused by EGF. GPCR inhibitor Cyclopamine V significantly diminished RCAS1 secretion mediated by GPCR ligands $(P<0.05)$.

\section{Phosphorylation of signal transducing molecules in RCAS1 shedding}

The phosphorylation of signal transducing molecules was investigated by Western blot after RCAS1 shedding stimulation. Though TPA induced phosphorylation of PKC- $\delta$, this could be strongly reduced by the MEK and PKC inhibitors PD98059 and GF1092034X (Fig. 3 A). In contrast, metalloproteinase, p38, and JNK inhibitors (GM6001, SB203580, and SP600125, respectively) and Akt inhibitor IV did not affect PKC- $\delta$ phosphorylation induced by TPA. Although ERK1/2 was phosphorylated by EGF in SiSo cells, this phosphorylation was drastically diminished by addition of EGFR and MEK inhibitors (AG1478 and PD98059) [Fig. 3 B]. Additionally, elevated phosphorylation levels of JNK and Akt were suppressed by adding SP600125 and Akt inhibitor IV, respectively.

\section{Analysis of K562 apoptosis induced by RCAS1}

The mechanism of apoptosis induced by RCAS1 in K562 cells was analyzed by using a co-culture system with SiSo and MCF-7 cells, or administering soluble RCAS1 to the culture medium. When K562 cells 
were cultured with SiSo cells, apoptotic death of K562 cells was induced. Fig. 4A shows that the Annexin- $\mathrm{V}$ positive ratio increased in an $\mathrm{E} / \mathrm{T}$ ratio-dependent fashion after day 4 of culture; $70.66 \%$ of K562 cells were apoptotic at a 20:1 E/T ratio. Apoptosis rates for K562 cells increased with SiSo cell number and culture length (Fig. 4 B). However, apoptosis of K562 cells was not induced by co-culture with MCF-7 cells (Fig. $4 \mathrm{C}$ and D).

Next, we investigated K562 cell apoptosis induced by soluble RCAS1. The Annexin-V positive ratio of K562 measured by flow cytometry showed that apoptosis increased with RCAS1 concentration and culture time; $89.81 \%$ of K562 cells were apoptotic with $10 \mathrm{U} / \mathrm{ml}$ of RCAS1 after 4 days (Fig. $5 \mathrm{~A}$ and $\mathrm{B}$ ). These data indicate that secreted but not membrane-anchored RCAS1 induces apoptosis in K562 cells. 


\section{Discussion}

This study investigated novel roles for RCAS1 in the induction of apoptosis. RCAS1 is secreted by ectodomain shedding induced by phorbol ester, pro-inflammatory cytokines, various stress-inducing stimuli, growth factors, and GPCR ligands. Although the physiological relevance of ectodomain shedding is well recognized, the signaling mechanisms activating this process are largely unknown. Ectodomain shedding is observed constitutively under normal culture conditions, but can often be stimulated by several activators. The phorbol ester TPA is often used to stimulate ectodomain shedding in vitro, whereby TPA induces phosphorylation of PKC- $\delta$, leading to metalloproteinase activation, which is thought to mediate ectodomain shedding [18]. Several growth factors, including EGF, may be involved in receptor tyrosine kinase activation, which in turn activate the Ras-MAPK signaling pathway that is a common regulator of the shedding of heparin-binding EGF-like growth factor (HB-EGF), transforming growth factor TGF- $\alpha$, tumor necrosis factor TNF- $\alpha$, L-selectin, and syndecan, among others [19]. GPCRs contribute to an additional pathway for RCAS1 shedding transactivation. The activation of receptor tyrosine kinases and GPCRs induces ectodomain shedding of growth factors that activate tyrosine kinase receptors, establishing a positive feedback loop. Although pro-inflammatory cytokines and stress activate both p38 and JNK, p38, rather than JNK, is the primary contributor to stimuli-induced ectodomain shedding of a number of membrane proteins $[20,21]$. The basal cleavage level of HB-EGF in the absence of exogenous 
growth factor stimulation was due to p38 signaling; the pathway mediated by p38 activation is distinct from the phorbol ester- and GPCR ligand-induced shedding cascade. The events occurring downstream of RCAS1 activation in these pathways and the metalloproteinases responsible for RCAS1 shedding are now under investigation.

Ectodomain shedding represents an important and efficient strategy to regulate the activities of a variety of transmembrane proteins involved in cell adhesion, signal transduction, or certain pathologies such as Alzheimer's disease or cancer [22]. RCAS1 suppresses growth and induces apoptosis in its receptor-expressing cells. Though the importance of the transmembrane domain for biological activity has been reported in the case of Fas ligand [23], this study shows that apoptosis is mainly induced by secreted but not membrane-anchored RCAS1. There are cases in which the soluble but not membrane-anchored forms of proteins are biologically active. In Drosophila, the EGFR ligand Spitz influences a subset of developmental processes that are regulated by EGFR but only the secreted form of Spitz triggers EGFR signaling cascades [24]. Processing of the membrane-anchored precursor form is required for biological activity of the Notch ligand Delta in Drosophila [25]. Regulation of the conversion of membrane-anchored proteins into a soluble form would be important to modify the action of such molecules, including RCAS1.

RCAS1 is found in the vaginal discharge of cervical cancer patients [26]. RCAS1 values are significantly higher in patients with uterine, ovarian, pancreatic, and gastrointestinal tract cancers than in healthy blood 
donors [1]. The serum RCAS1 level was higher in patients with gastrointestinal tract cancers than in a control group and was significantly elevated in patients with lymph node involvement compared to lymph node-negative patients [27]. In addition, malignant pleural effusions had significantly higher RCAS1 concentrations than did non-malignant effusions [28]. Moreover, RCAS1 values were statistically associated with the response to treatment for patients with uterine and ovarian cancer [16, 17]. Growth of K562 cells cultured in the presence of serum from these cancer patients was significantly inhibited relative to cells grown with serum from healthy blood donors. This suppressive effect on cell growth could be partially reversed after immunodepletion of RCAS1. These data indicate that RCAS1 may be a suitable biomarker for uterine and ovarian cancer by virtue of its ability to predict the results of medical treatment and inhibit the cell growth of its putative receptor-expressing cells.

The activity of RCAS1 in cancer progression may be enhanced by ectodomain shedding. First, ectodomain shedding is shown to be an important step in RCAS1 induction of apoptosis. Theoretically, the mode of action of secreted molecules could be distinct from those of membrane-anchored proteins in the following respect: membrane-anchored ligands can transmit signals only to neighboring cells, while soluble ligands can diffuse and act at a distance. For example, shedding of the extracellular domain of the adhesion protein L-selectin disrupts binding of leukocytes to endothelial cells and may prevent their recruitment to inflammation sites [29]. The consequent diffusion and systemic release of soluble TNF- $\alpha$ 
causes cachexia, which cannot be induced by transmembrane TNF- $\alpha$ [30]. We previously investigated an association between the level of tumor cell RCAS1 expression or secretion and the number of lymphocytes in patients with uterine cancer. The number of apoptotic lymphocytes significantly increased with RCAS1 expression level in primary lesions and metastatic lymph nodes [31]. Furthermore, the population of peripheral lymphocytes was reduced with a reverse correlation to the serum RCAS1 concentration [16]. Thus, RCAS1 may contribute to tumor progression by affecting immune surveillance not only locally but also systemically. RCAS1 is also thought to be involved in the acquisition of malignant phenotypic characteristics and tumor progression through the remodeling of stromal tissue [1]. The important role of stromal tissue in supporting tumorigenic processes has been clarified [32]. During tumor progression, invasion, and metastasis, active cross-talk occurs between tumor cells and the stroma that is mediated mainly by direct cell-cell contact or by paracrine cytokine and growth factor signaling [33]. RCAS1 expression is associated with increased MMP-1 and laminin-5 levels in tumor cells, but is also correlated with a loss of vimentin in stromal tissue [5, 6]. Additionally, introduction of the RCAS1-encoding gene into COS-7 cells increased MAPK phosphorylation and accelerated in vivo tumor growth by promoting angiogenesis [7]. We show here that RCAS1 is secreted by ectodomain shedding through an activation of the MAPK pathway, which promotes cell growth. Shedding of soluble molecules is often enhanced in tumor cells, suggesting that signaling pathways that are activated in transformed cells 
may induce ectodomain shedding [34]. Such a potentially important role for shedding in tumor formation is further supported by a transgenic mouse model showing that mice overexpressing cleavable, but not uncleavable, TGF- $\alpha$ have an increased incidence of tumor development [35]. This suggests that ectodomain shedding may be part of a positive feedback mechanism in the case of TGF- $\alpha$. Moreover, TNF- $\alpha$ and Fas L, which are pivotal regulators of apoptosis, also induce cell proliferation [36, 37]. Therefore, overexpression and ectodomain shedding of RCAS1 may contribute to tumor progression via not only stromal remodeling but also tumor cell proliferation.

Taken together, these data indicate that RCAS1 is a unique molecule that may contribute to tumor progression by its multiple functions. Further exploration regarding the regulatory mechanisms involved in the conversion of membrane-anchored RCAS1 into its soluble form should aid the development of novel therapeutic strategies against human malignancies by targeting RCAS1. 


\section{Conflict of interest statement}

None declared.

\section{Acknowledgments}

We thank Ms. Megumi Ito, Ms. Shoko Inagaki, and Ms. Yuki Honda for technical assistance. This work was supported in part by a grant-in-aid for scientific research from the Japan Society for the Promotion of Science (Numbers 21592134). This work was done in part at the Station for Collaborative Research and at the Morphology Core, Graduate School of Medical Sciences, Kyushu University. 


\section{References}

1. K. Sonoda, S. Miyamoto, M. Nakashima, N. Wake, The biological role of unique molecule RCAS1: a bioactive marker that induces connective tissue remodeling and lymphocyte apoptosis, Front. Biosci. 13 (2008) 1106-1116.

2. K. Sonoda, T. Kaku, T. Kamura, M. Nakashima, T. Watanabe, H. Nakano, Tumor-associated antigen 22-1-1 expression in the uterine cervical squamous neoplasia, Clin. Cancer Res. 4 (1998) 1517-1520.

3. K. Sonoda, T. Kaku, T. Hirakawa, H. Kobayashi, S. Amada, K. Sakai, M. Nakashima, T. Watanabe, H. Nakano, The clinical significance of tumor-associated antigen RCAS1 expression in the normal, hyperplastic, and malignant uterine endometrium, Gynecol. Oncol. 79 (2000) 424-429.

4. M. Nakashima, K. Sonoda K, T. Watanabe, Inhibition of cell growth and induction of apoptotic cell death by the human tumor-associated antigen RCAS1, Nat. Med. 5 (1999) 938-942.

5. K. Sonoda, S. Miyamoto, T. Hirakawa, H. Yagi, F. Yotsumoto, M. Nakashima, T. Watanabe, H. Nakano, Invasive potency related to RCAS1 expression in uterine cervical cancer, Gynecol. Oncol. 99 (2005) 189-198.

6. K. Sonoda, S. Miyamoto, H. Kobayashi, S. Ogawa, K. Okugawa, S. Taniguchi, N. Wake, The level of RCAS1 expression is inversely correlated with the number of vimentin-positive stromal cells in epithelial ovarian cancer, Int. J. Gynecol. Cancer 19 (2009) 838-843. 
7. K. Sonoda, S. Miyamoto, A. Yamazaki, H. Kobayashi, M. Nakashima, E. Mekada, N. Wake, Biologic significance of receptor-binding cancer antigen expressed on SiSo cells (RCAS1) as a pivotal regulator of tumor growth through angiogenesis in human uterine cancer, Cancer 110 (2007) 1979-1990.

8. Y. Izumi, M. Hirata, H. Hasuwa, R. Iwamoto, T. Umata, K. Miyado, Y. Tamai, T. Kurisaki, A. Sehara-Fujisawa, S. Ohno, E. Mekada, A metalloprotease-disintegrin, MDC9/meltrin- $\gamma / \mathrm{ADAM} 9$ and $\mathrm{PKC} \delta$ are involved in TPA-induced ectodomain shedding of membrane-anchored heparin-binding EGF-like growth factor, EMBO. J. 17 (1998) 7260-7272.

9. J. Massague, A. Pandiella, Membrane-anchored growth factors, Annu. Rev. Biochem. 62 (1993) 515-541.

10. M. Golembo, E. Raz, B. Shilo, The Drosophila embryonic midline is the site of Spitz processing and induces activation of the EGF receptor in the ventral ectoderm, Development 122 (1996) 3363-3370.

11. J.G. Flanagan, D.C. Chan, P. Leder, Transmembrane from of the kit ligand growth factors is determined by alternative splicing and is missing in the SId mutant, Cell 64 (1991) 1025-1035.

12. S. Davis, N.W. Gale, T.H. Aldrich, P.C. Maisonpierre, V. Lhotak, T. Pawson, M. Goldfarb, G.D. Yancopoulos, Ligands for EPH-related receptor tyrosine kinases that require membrane attachment or clustering for activity, Science 266 (1994) 816-819.

13. K. Sonoda, M. Nakashima, T. Saito, S. Amada, T. Kamura, H. Nakano, 
T. Watanabe, Establishment of a new human uterine cervical adenocarcinoma cell line, SiSo, and its reactivity to anti-cancer reagents, Int. J. Oncol. 6 (1995) 1099-1104.

14. Q.X. Zhang, Å. Borg, S.A.W. Fuqua, An exon 5 deletion variant of the estrogen receptor frequently coexpressed with wild-type estrogen receptor in human breast cancer, Cancer Res. 53 (1993) 5882-5884.

15. L.C. Andersson, K. Nilsson, C.G. Gahmberg, K562-A human erythroleukemia cell line, Int. J. Cancer 23 (1979) 143-147.

16. K. Sonoda, S. Miyamoto, T. Hirakawa, H. Yagi, F. Yotsumoto, M. Nakashima, T. Watanabe, H. Nakano, Clinical significance of RCAS1 as a biomarker of uterine cancer, Gynecol. Oncol. 103 (2006) 924-931.

17. K. Sonoda, S. Miyamoto, F. Yotsumoto, H. Yagi, M. Nakashima, T. Watanabe, H. Nakano, Clinical significance of RCAS1 as a biomarker of ovarian cancer, Oncol. Rep. 17 (2007) 623-628.

18. J. Arribas, L. Coodly, P. Vollmer, T.K. Kishimoto, S. Rose-John, J. Massague, Diverse cell surface protein ectodomains are shed by a system sensitive to metalloprotease inhibitors, J. Biol. Chem. 271 (1996) 11376-11382.

19. R. Iwamoto, E. Mekada, Heparin-binding EGF-like growth factor: a juxtacrine growth factor, Cytokine Growth Factor Rev. 11 (2000) 335-344.

20. S.B. Rizoli, O.D. Rotstein, A. Kapus, Cell volume-dependent regulation of L-selectin shedding in neutrophils, J. Biol. Chem. 274 (1999) 22072-22080. 
21. H. Takenobu, A. Yamazaki, M. Hirata, T. Umata, E. Mekada, The stress- and inflammatory cytokine-induced ectodomain shedding of heparin-binding epidermal growth factor-like growth factor is mediated by $\mathrm{p} 38$ MAPK, distinct from the 12-O-tetradecanoylphorbol-13-acetate- and lysophosphatidic acid-induced signaling cascades, J. Biol. Chem. 278 (2003) 17255-17262.

22. J. Arribas, A. Borroto, Protein ectodomain shedding, Chem. Rev. 102 (2002) 4627-4637.

23. M. Tanaka, T. Itai, M. Adachi, S. Nagata, Down regulation of Fas ligand by shedding, Nat. Med. 4 (1998) 31-36.

24. R. Schweitzer, M. Shaharabany, R. Segar, B.Z. Shilo, Secreted Spitz triggers the DER signaling pathway and is a limiting component in embryonic ventral ectoderm determination, Genes Dev. 9 (1995) 1518-1529.

25. H. Qi, M.D. Rand, X. Wu, N. Sestan, W. Wang, P. Rakic, T. Xu, S. Artavanis-Tsakonas, Processing of the Notch ligand delta by the metalloprotease Kuzubanian, Science 238 (1999) 91-94.

26. K. Sonoda, M. Nakashima, T. Kaku, T. Kamura, H. Nakano, T. Watanabe, A novel tumor-associated antigen expressed in human uterine and ovarian carcinomas, Cancer 77 (1996) 1501-1509.

27. N. Coban, H. Ozkan, S. Koklu, O. Yuksel, M.C. Kockar, T. Akar, N. Ormeci, The utility of serum receptor-binding cancer antigen expressed on SiSo cells in gastrointestinal tract cancers, Can. J. Gastroenterol. 20 
(2006) 593-596.

28. K. Aoe, A. Hiraki, T. Maeda, T. Murakami, K. Yamazaki, K. Sugi, H. Takeyama, Soluble receptor-binding cancer antigen expressed on SiSo cells in pleural fluid: a potential diagnostic marker for malignant pleural effusion, Chest 126 (2004) 1195-1197.

29. S.D. Rosen, C.R. Bertozzi, The selectins and their ligands, Curr. Opin. Cell Biol. 6 (1994) 663-673.

30. K.J. Tracey, A. Cerami, Metabolic responses to cachectin/TNF. A brief review, Ann. N.Y. Acad. Sci. 587 (1990) 325-331.

31. K. Sonoda, S. Miyamoto, T. Hirakawa, H. Yagi, F. Yotsumoto, M. Nakashima, T. Watanabe, H. Nakano, Association between RCAS1 expression and microenvironmental immune cell death in uterine cervical cancer, Gynecol. Oncol. 97 (2005) 772-779.

32. J.B. Kim, R. Stein, M.J. O'Hare, Tumor-stromal interactions in breast cancer: the role of stroma in tumorigenesis, Tumor Biol. 26 (2005) 173-185.

33. N.A. Bhowmick, H.L. Moses, Tumor-stromal interactions, Curr. Opin. Genet. Dev. 15 (2005) 97-101.

34. H. Fan, R. Derynck, Ectodomain shedding of TGF- $\alpha$ and other transmembrane proteins is induced by receptor tyrosine kinase activation and MAP kinase signaling cascades, EMBO. J. 18 (1999) 6962-6972.

35. E.P. Sandgren, N.C. Luetteke, R.E. Palmiter, R.L. Brinster, D.C. Lee, Overexpression of TGF- $\alpha$ in transgenic mice: induction of epithelial 
hyperplasia, pancreatic metaplasia and carcinoma of the breast, Cell 61 (1990) 1121-1135.

36. G. Natoli, A. Costanzo, F. Guido, F. Moretti, M. Lavrero, Apoptotic, non-apoptotic, and anti-apoptotic pathways of tumor necrosis factor signaling, Biochem. Pharmacol. 56 (1998) 915-920.

37. H. Wajant, K. Pfizenmaier, P. Scheurich, Non-apoptotic Fas signaling, Cytokine Growth Factor Rev. 14 (2003) 53-66. 


\section{Figure legends}

Figure 1

RCAS1 expression after several kinds of stimulation that induce ectodomain shedding. The flow cytometric analysis showed that both SiSo and MCF-7 expressed RCAS1. RCAS1 expression was diminished in SiSo (A) but was not changed in MCF-7 (B) after stimulation. Negative control staining was done using mouse IgM.

Figure 2

RCAS1 secretion after stimulation that induces ectodomain shedding. (A) The concentration of RCAS1 in the culture supernatant was measured by ELISA. SiSo secreted RCAS1, which significantly increased after shedding stimulation (a). MCF-7 did not secrete RCAS1 even after stimulation (b). (B) RCAS1 secretion was decreased in the presence of inhibitors. Asterisks indicate statistical significance compared with untreated condition (A) or each stimulation state without inhibitors (B) $(P<0.05)$.

Figure 3

The phosphorylation of signal transducing molecules in SiSo cells after TPA (A) and EGF (B) stimulation in the presence or absence of several inhibitors. 
Figure 4

Apoptosis of K562 was induced in cultures with SiSo but not with MCF-7. (A) The Annexin-V positive cell ratio of PKH-labeled K562 cells cultured with SiSo cells for 4 days. The percentage of PKH and Annexin-V double positive cells is shown. (B) The Annexin-V positive cell ratio of K562 increased with the E/T ratio and culture period with SiSo. (C) The Annexin-V positive cell ratio of PKH-labeled K562 cells cultured with MCF-7 cells after 4 days. (D) Annexin-V positive K562 cells were not detected in MCF-7 co-cultures. Asterisks indicate a statistical significance compared with untreated conditions on the same day $(P<0.05)$.

Figure 5

Secreted RCAS1 induces apoptosis in K562 cells. (A) The Annexin-V positive ratio of K562 cells measured by flow cytometry (numbers represent the percentage of Annexin-V positive cells). (B) The Annexin-V positive K562 cell population increased with both RCAS1 concentration and culture length. Asterisk shows a statistical significance compared with $0 \mathrm{U} / \mathrm{ml}$ treatment on the same day $(P<0.05)$. 
Fig. $1 \mathrm{~A}$
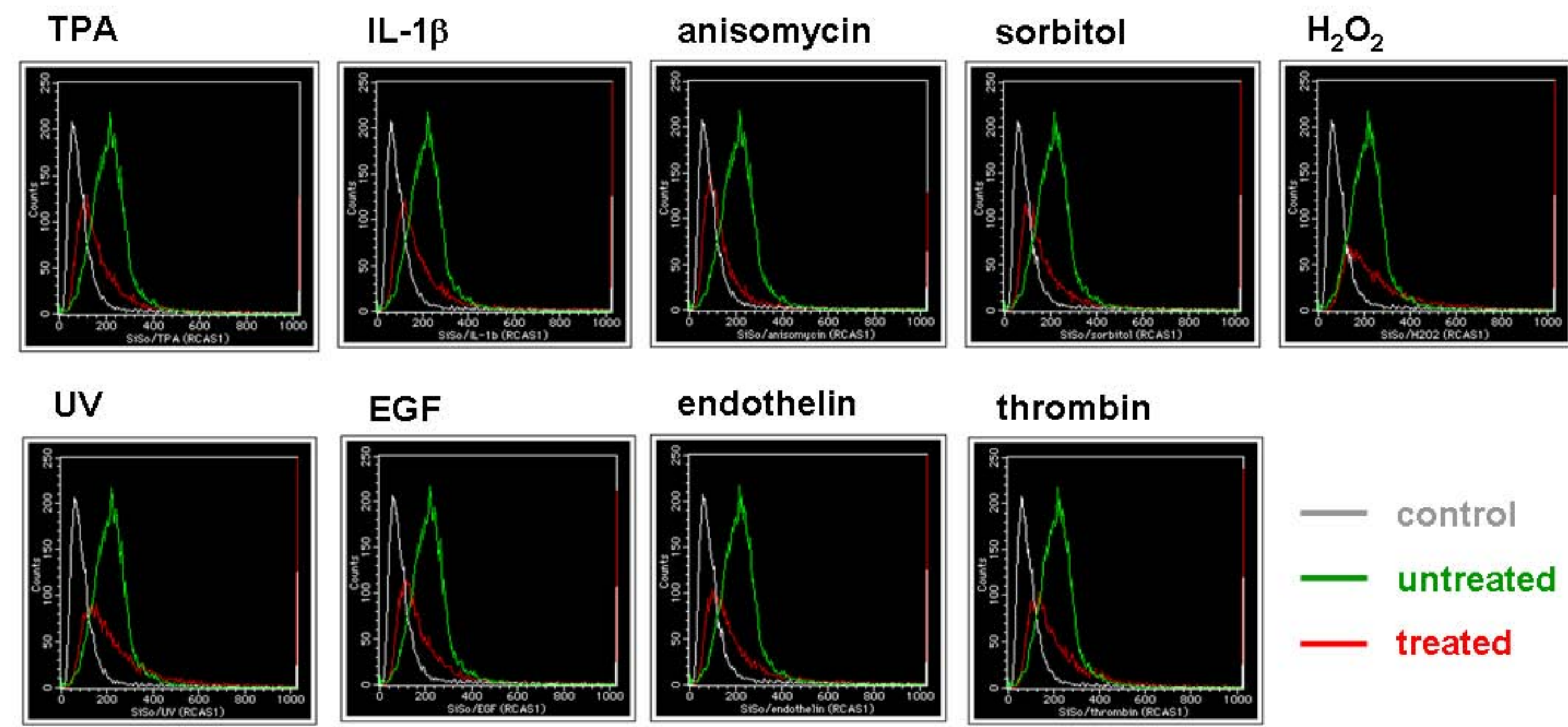

endothelin

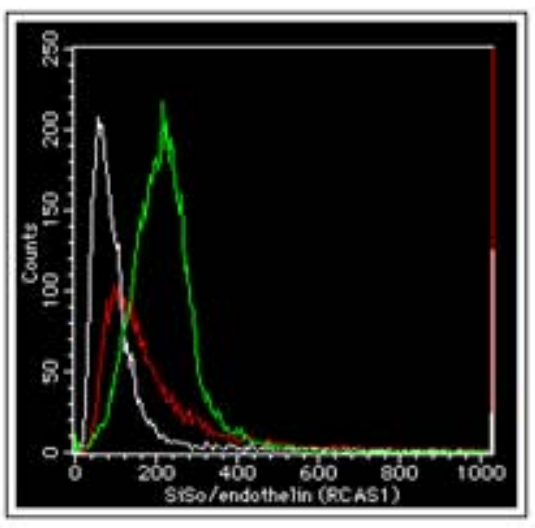

thrombin

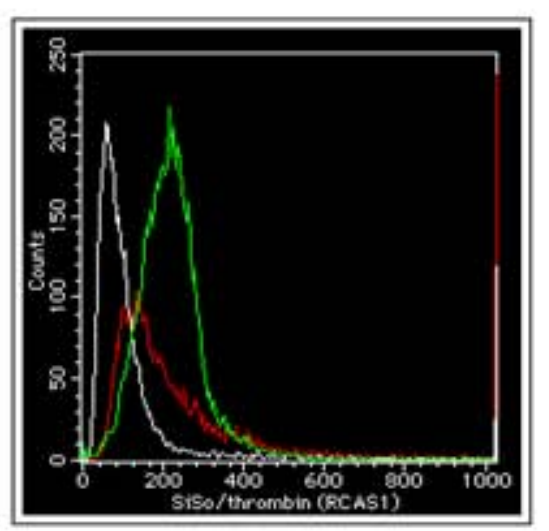

_ control

— untreated

— treated 
Fig. $1 \mathrm{~B}$
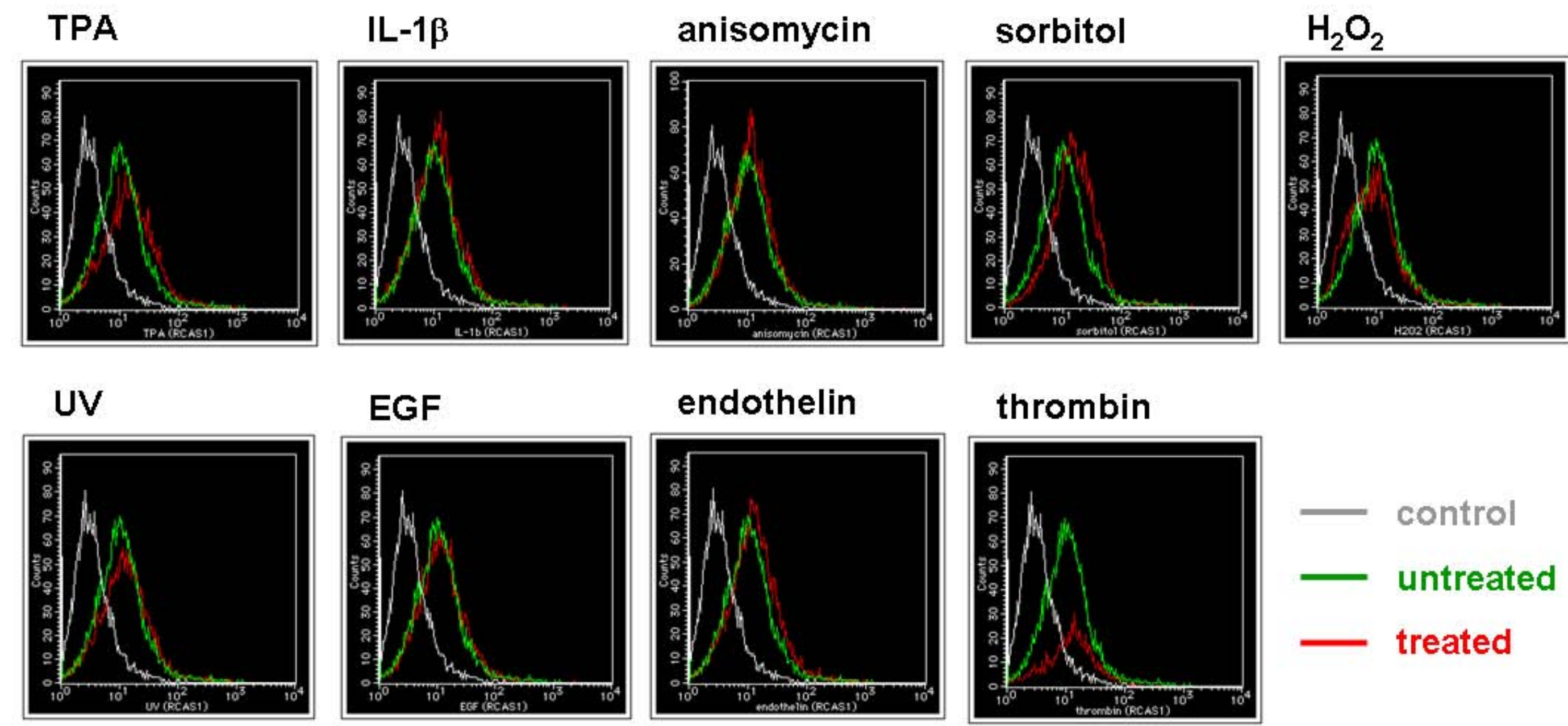
Fig. $2 \mathrm{~A}$

(a) SiSo

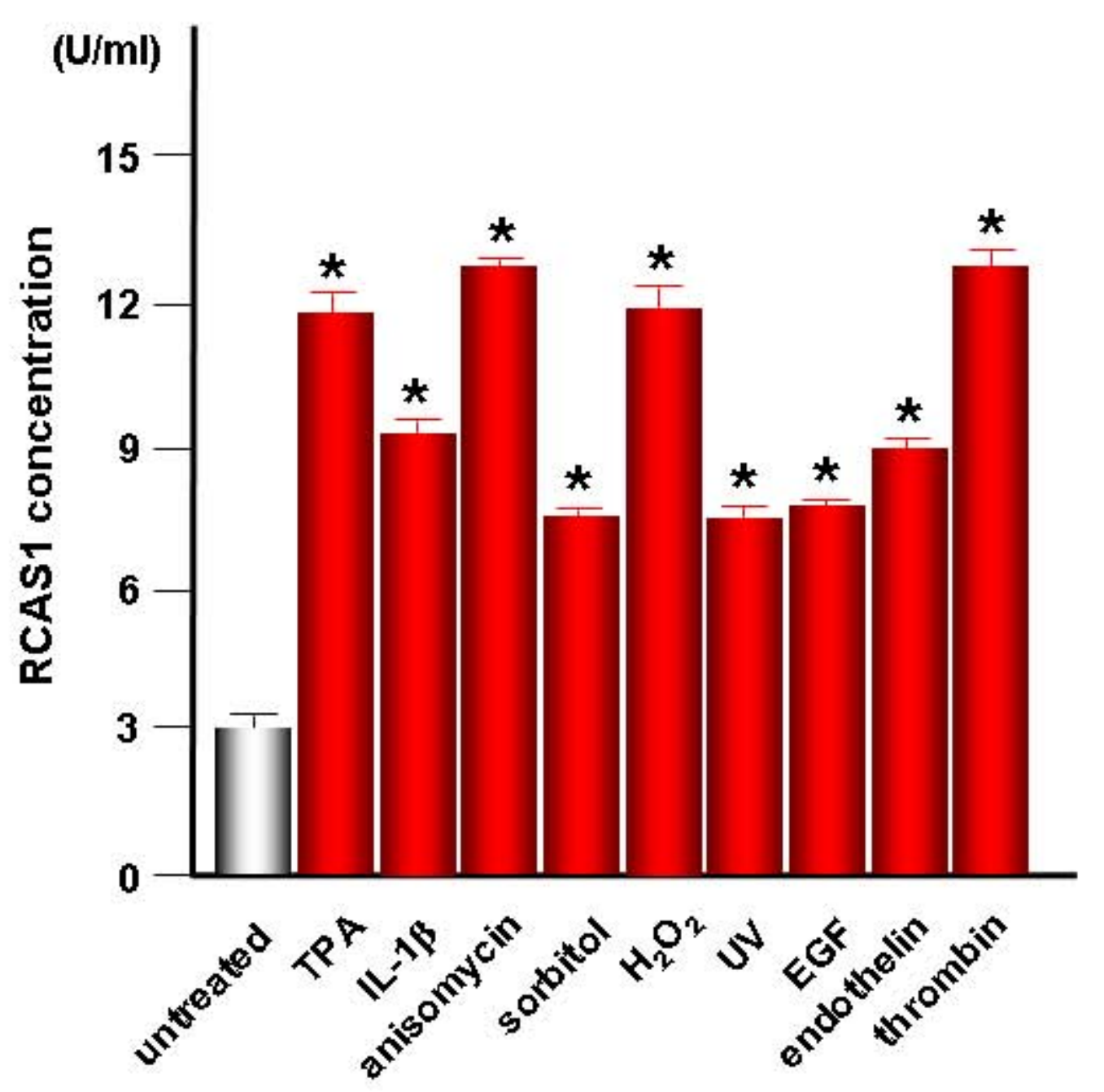

(b) MCF-7

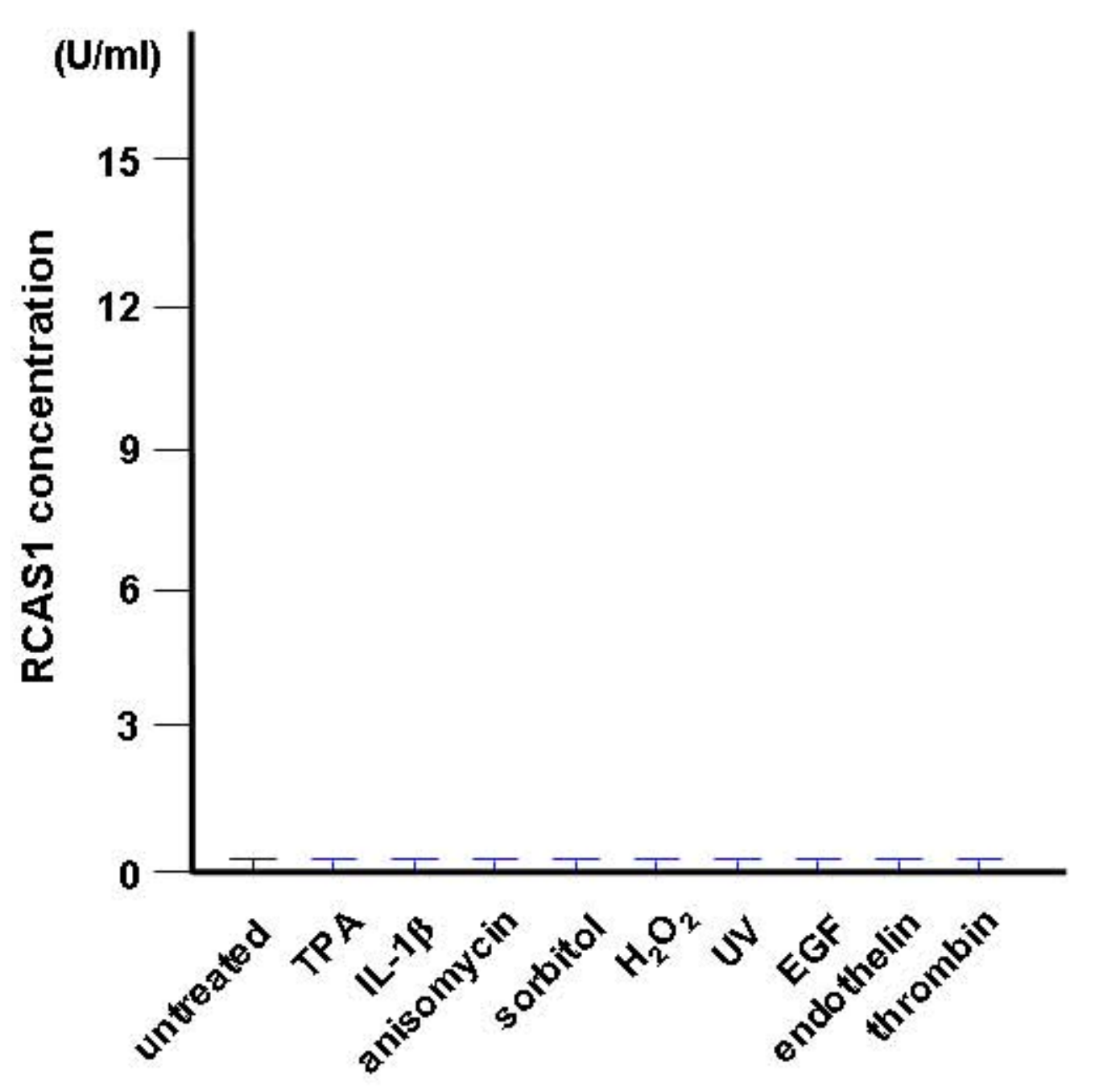


Fig. 2 B
(a) Phorbol ester
(b) EGF
(c) GPCR ligand
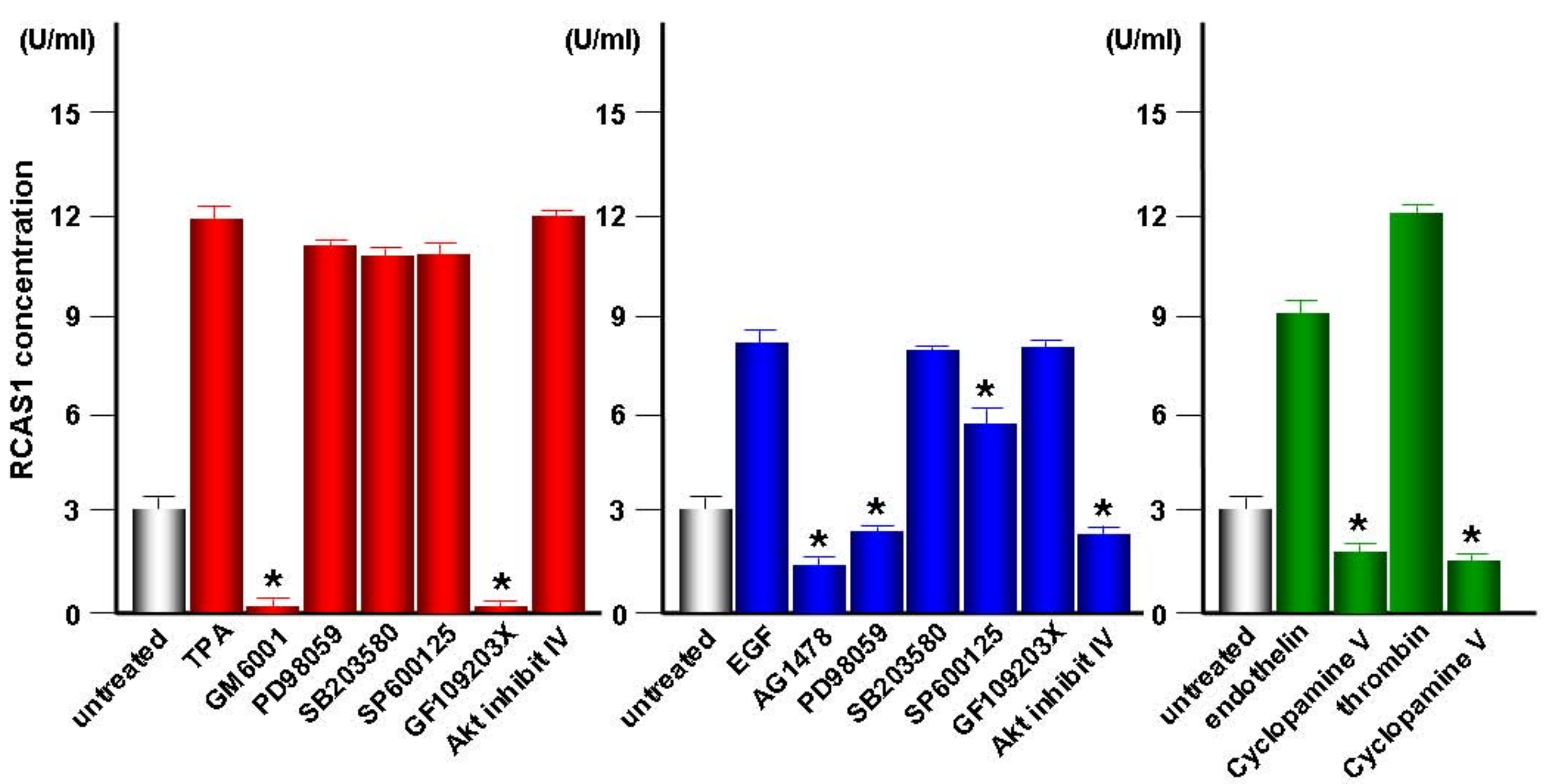
Fig. $3 \mathrm{~A}$

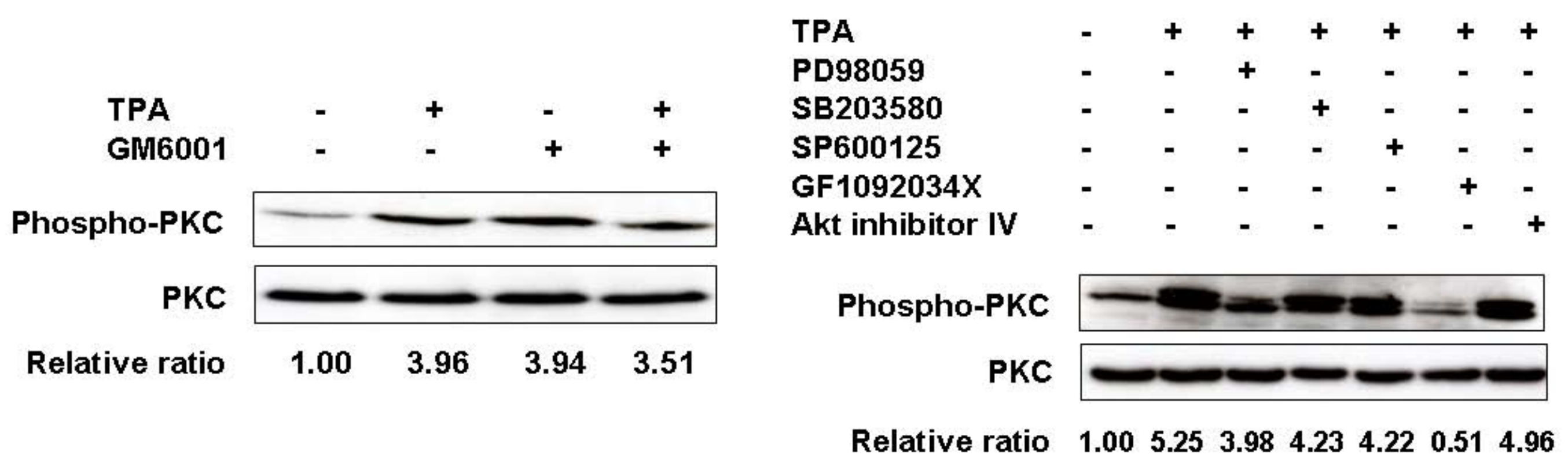


Fig. 3 B

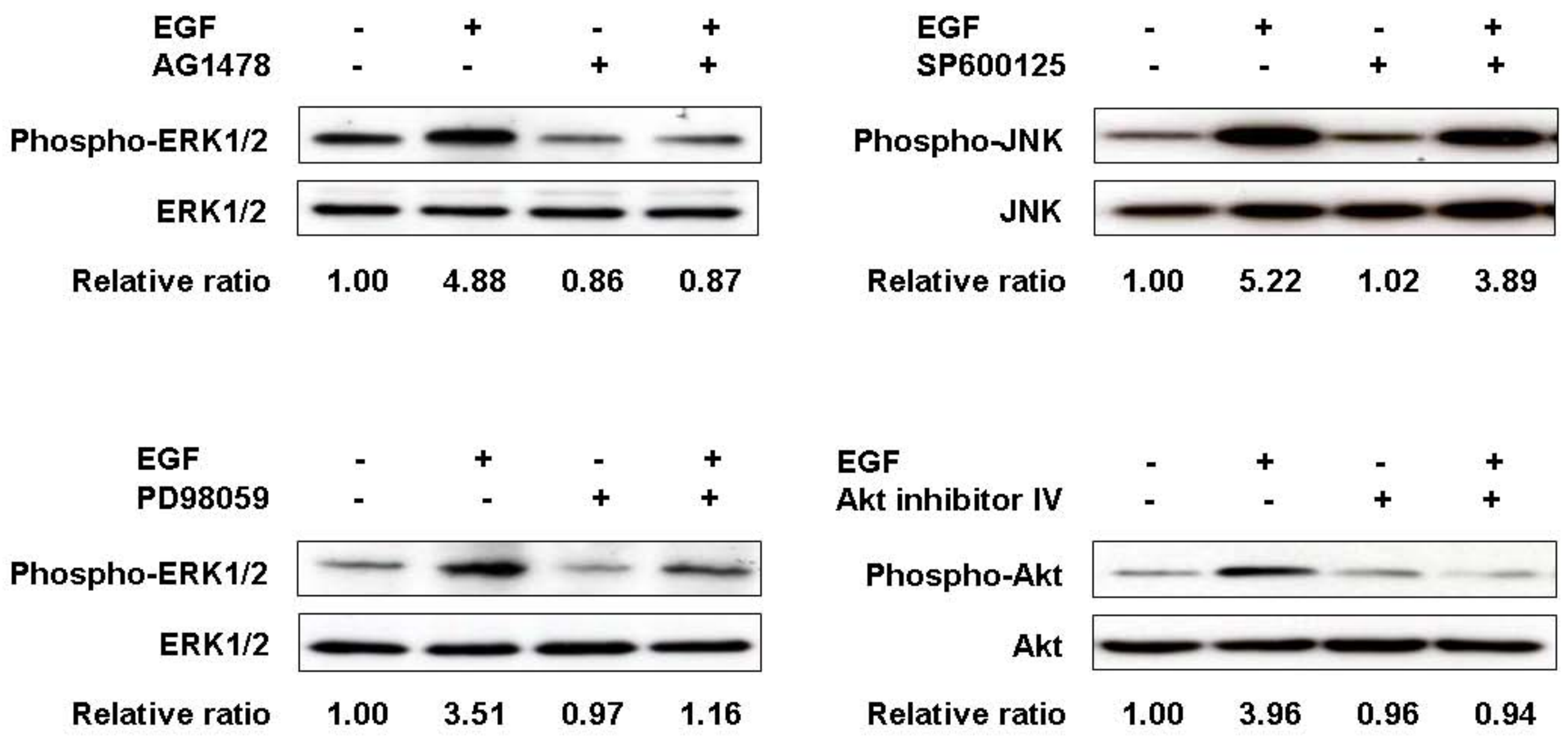


Fig. $4 \mathrm{~A}$

\section{untreated}

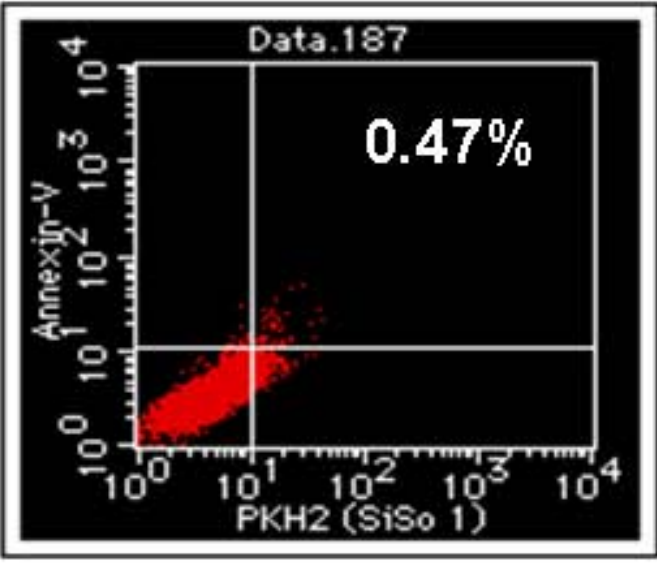

\section{$E / T=7: 1$}

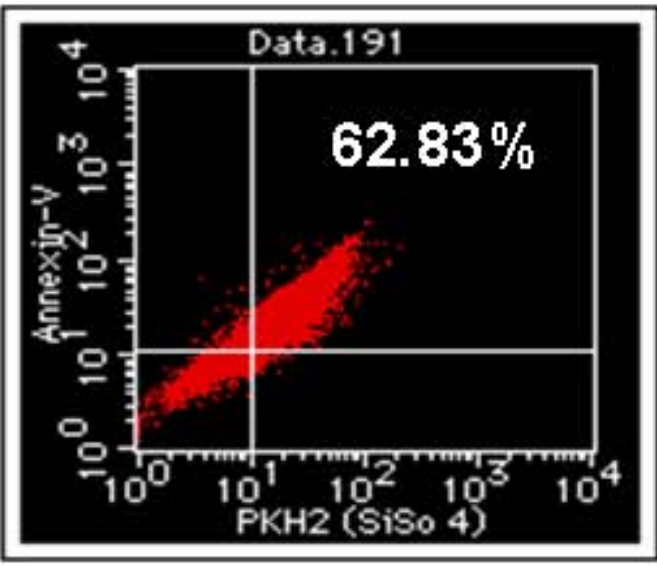

$E / T=1: 1$

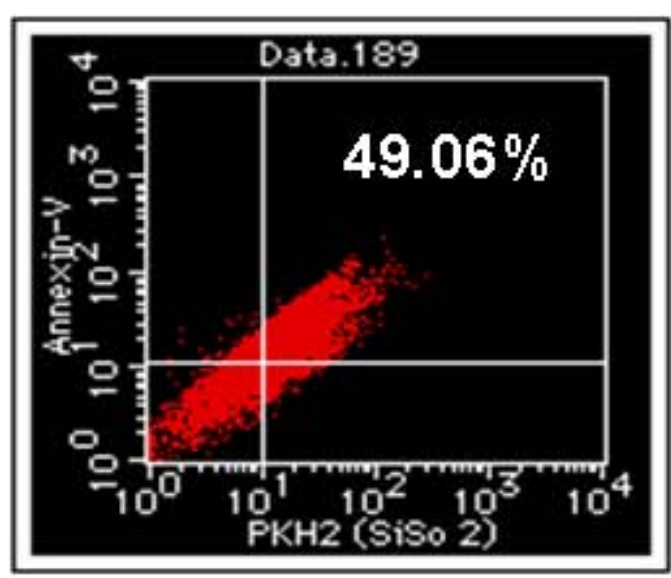

$E / T=10: 1$

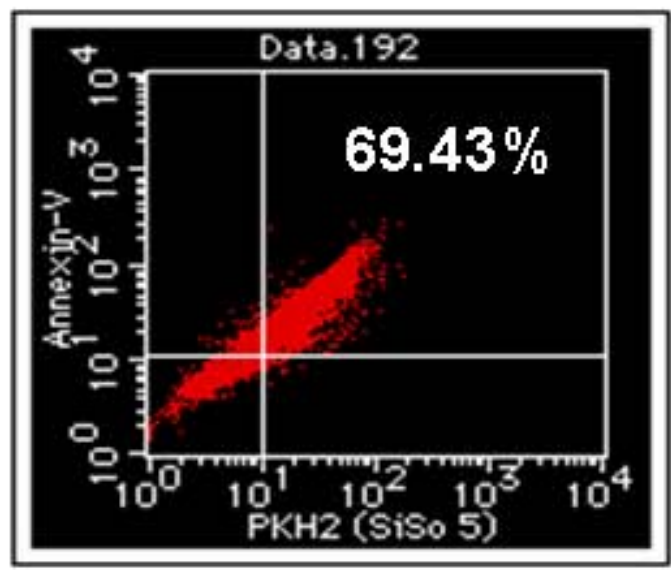

$E / T=5: 1$

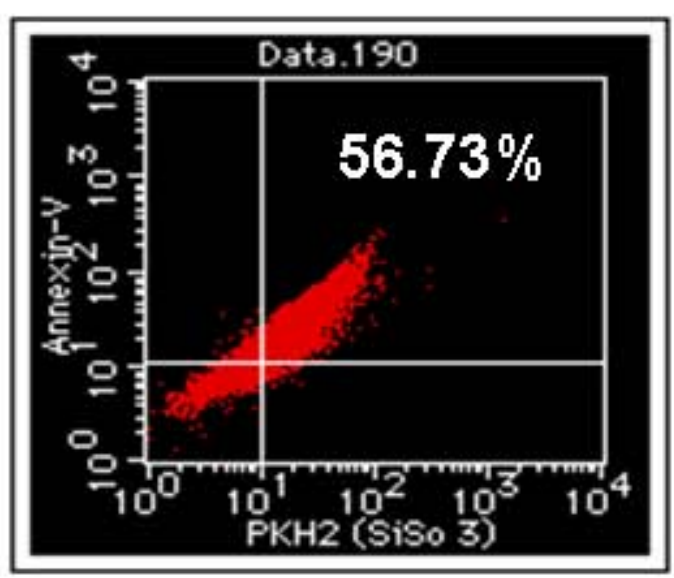

\section{$E / T=20: 1$}

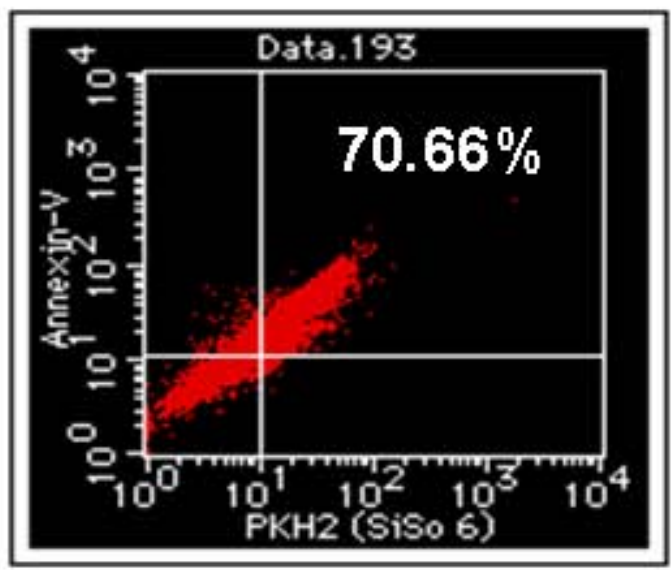


Fig. 4 B

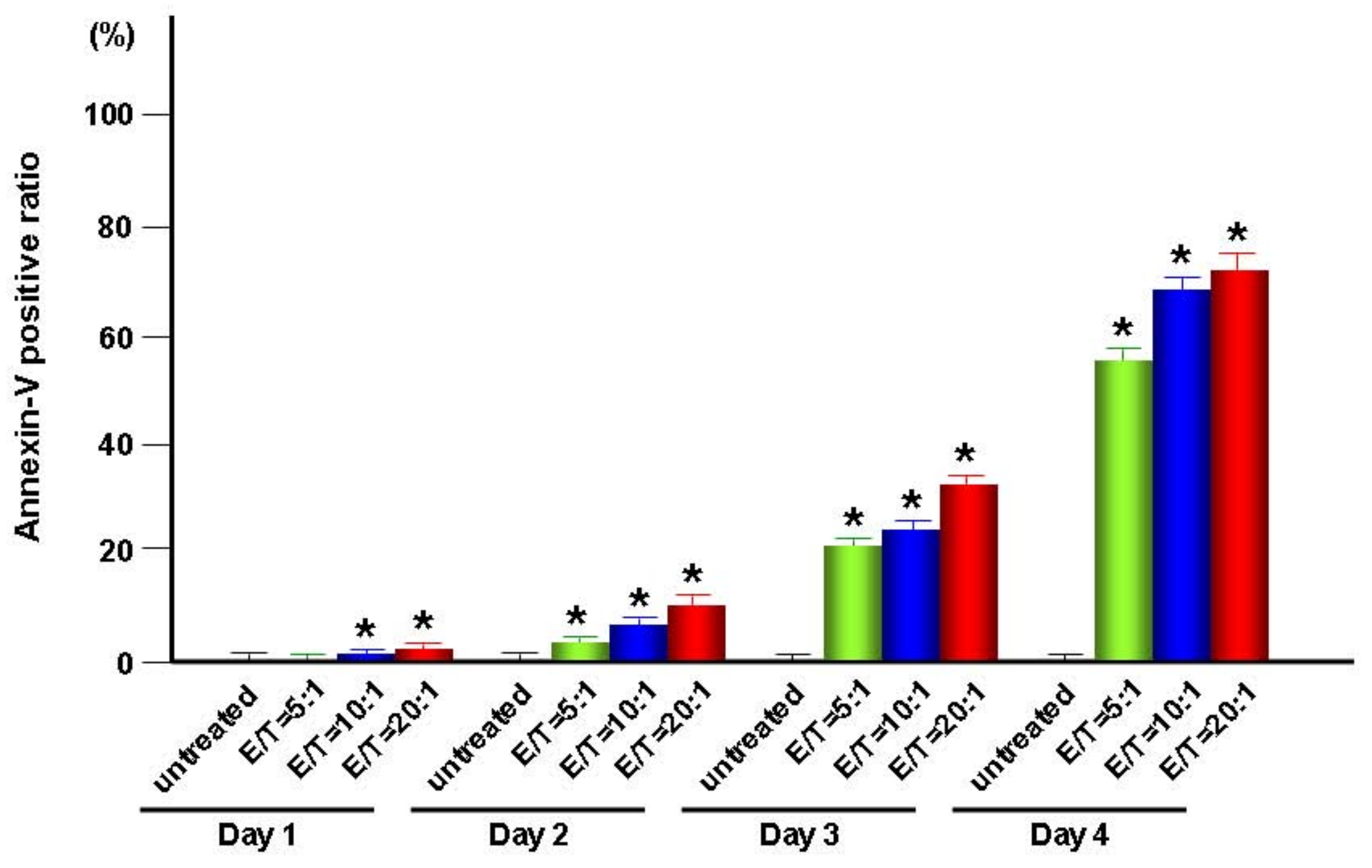


Fig. $4 \mathrm{C}$

\section{untreated}

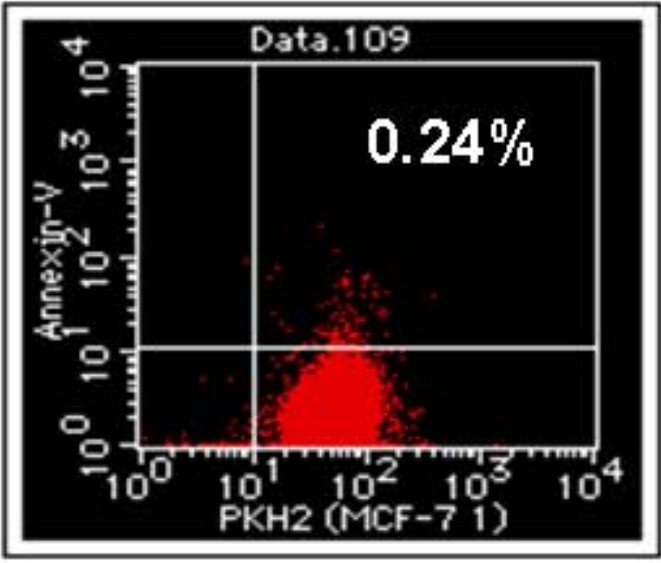

$E / T=7: 1$

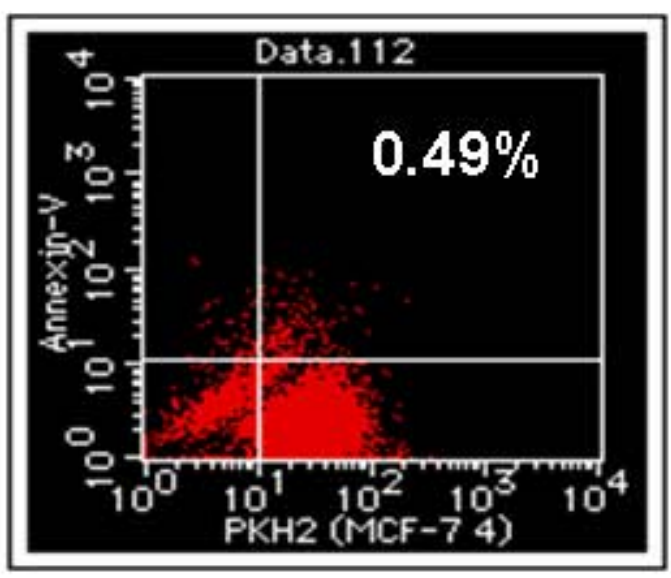

$E / T=1: 1$

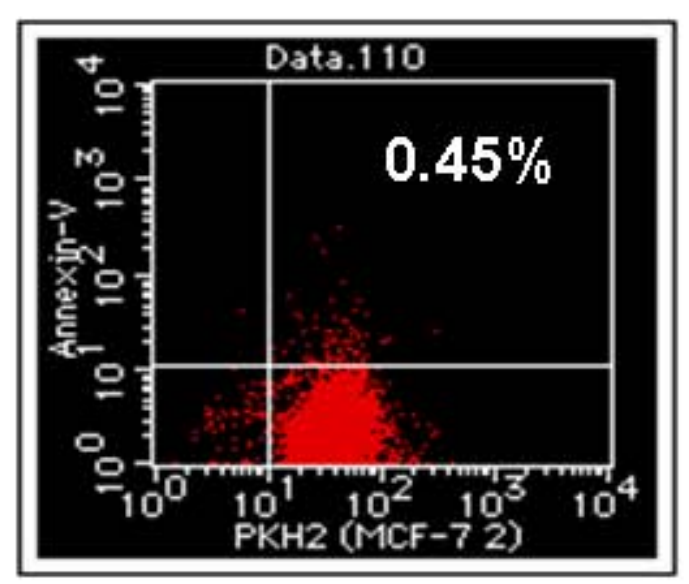

$E / T=10: 1$

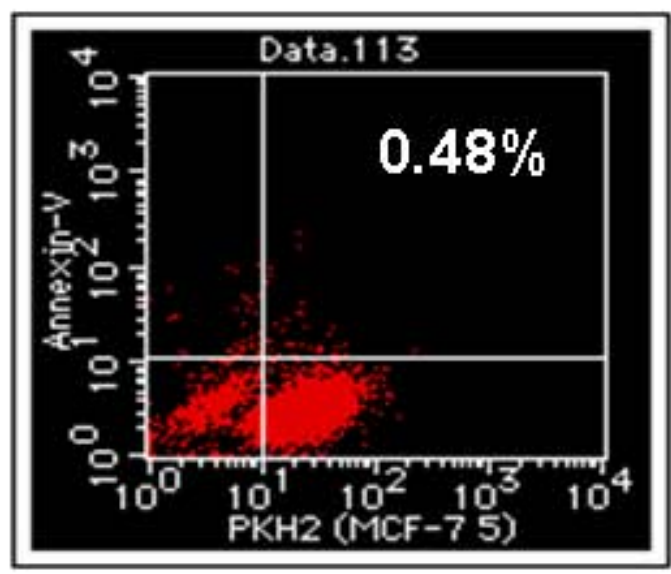

$E / T=5: 1$

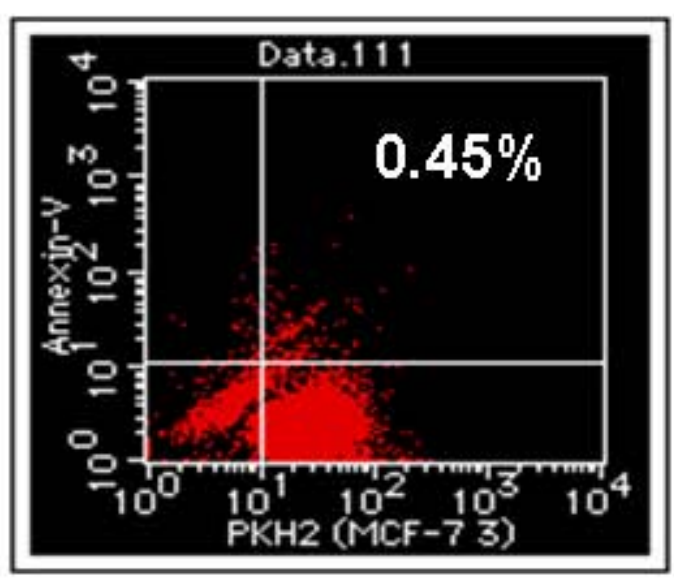

\section{$E / T=20: 1$}

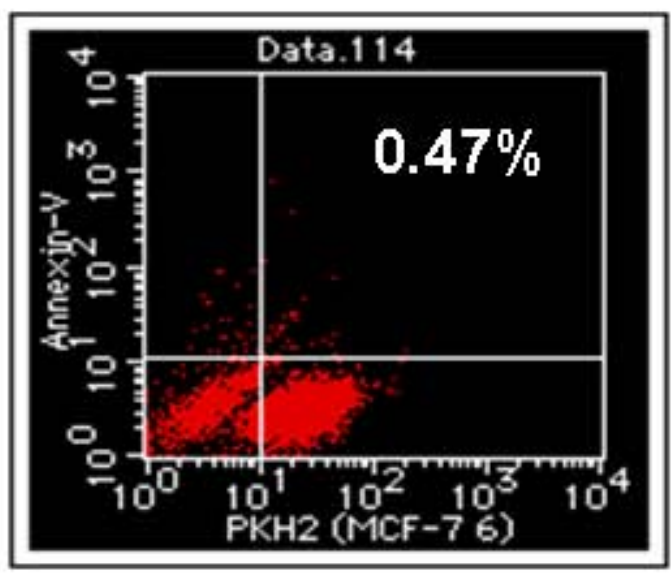


Fig. 4 D

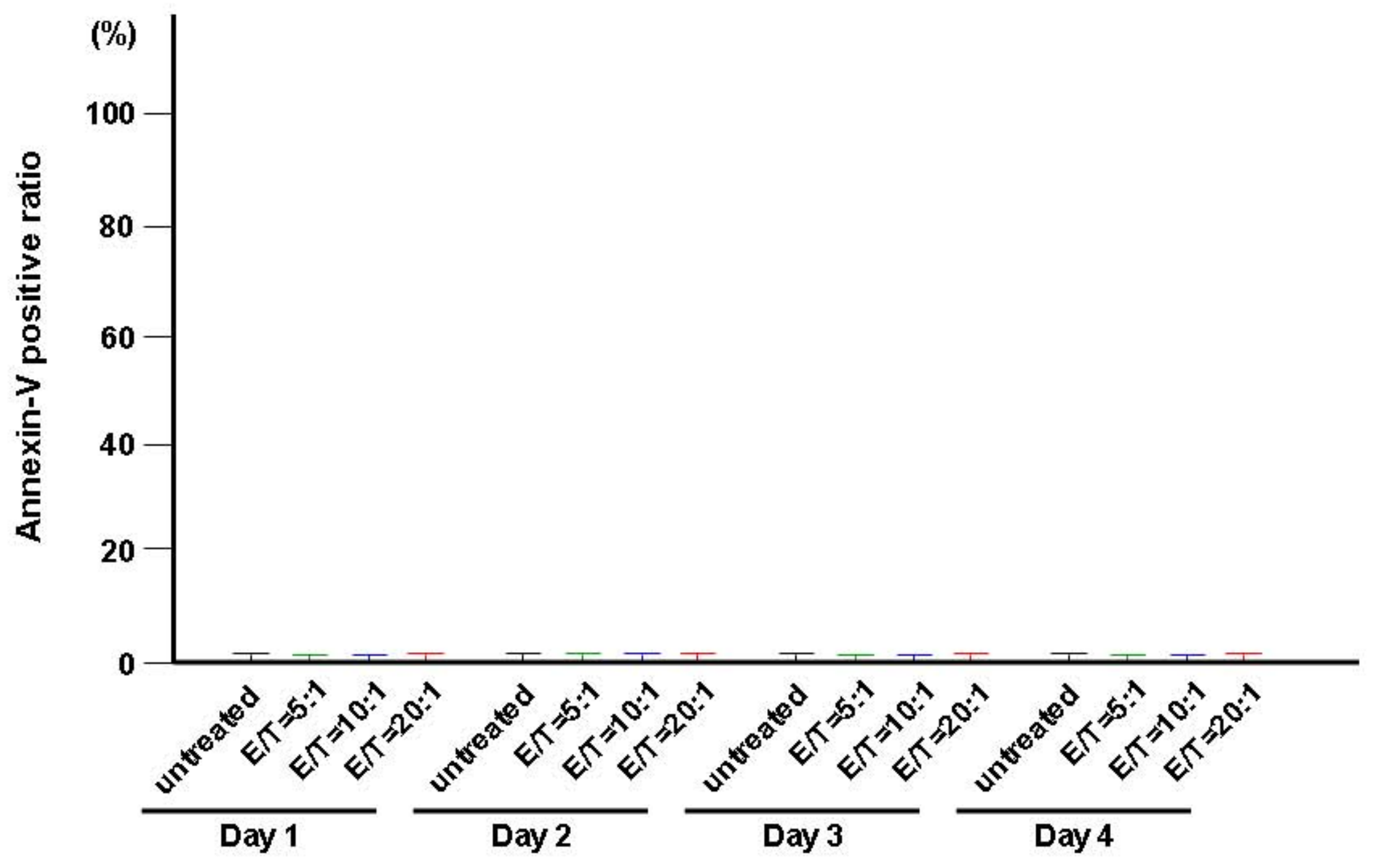


Fig. $5 \mathrm{~A}$

$0 \mathrm{U} / \mathrm{ml}$

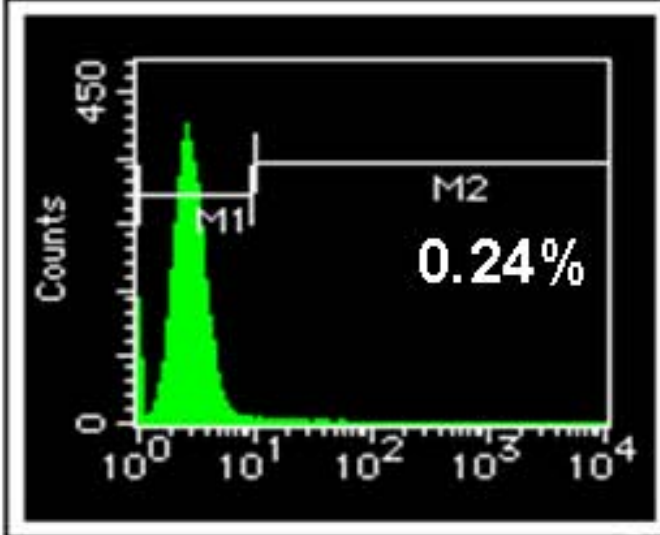

$3 \mathrm{U} / \mathrm{ml}$

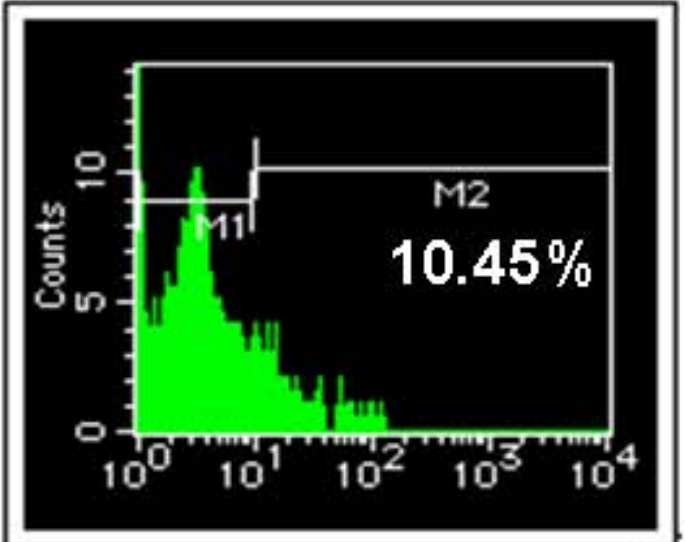

$1 \mathrm{U} / \mathrm{ml}$

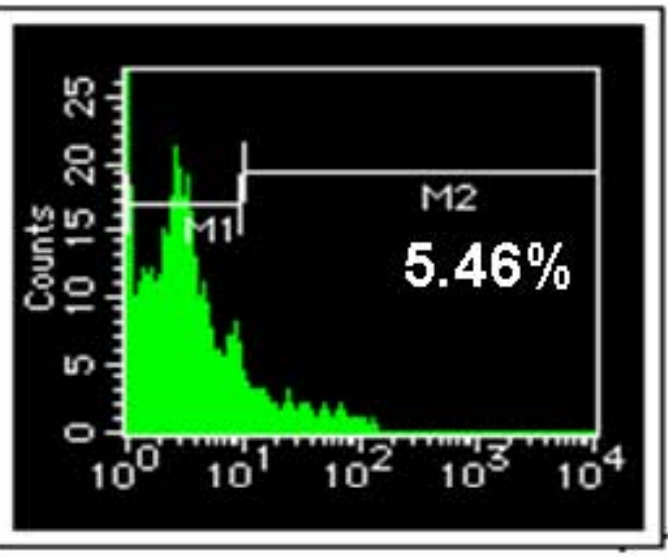

$5 \mathrm{U} / \mathrm{ml}$

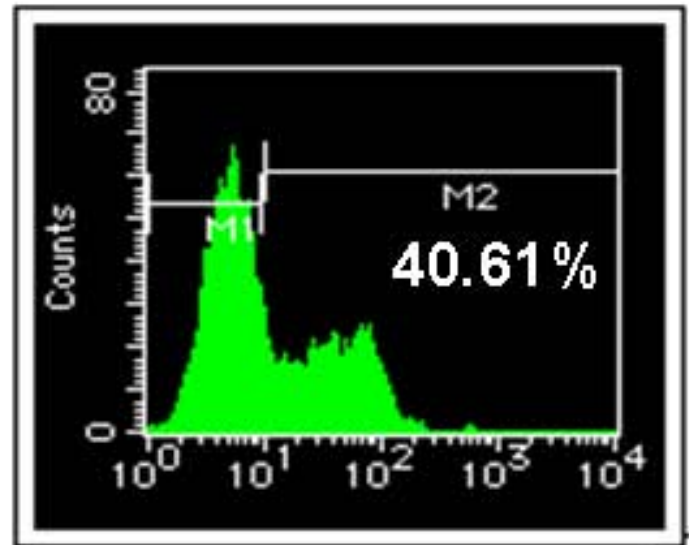

$2 \mathrm{U} / \mathrm{ml}$

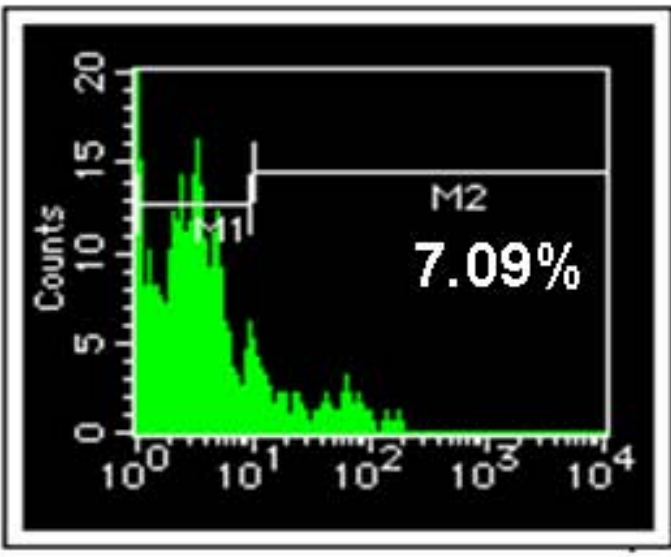

$10 \mathrm{U} / \mathrm{ml}$

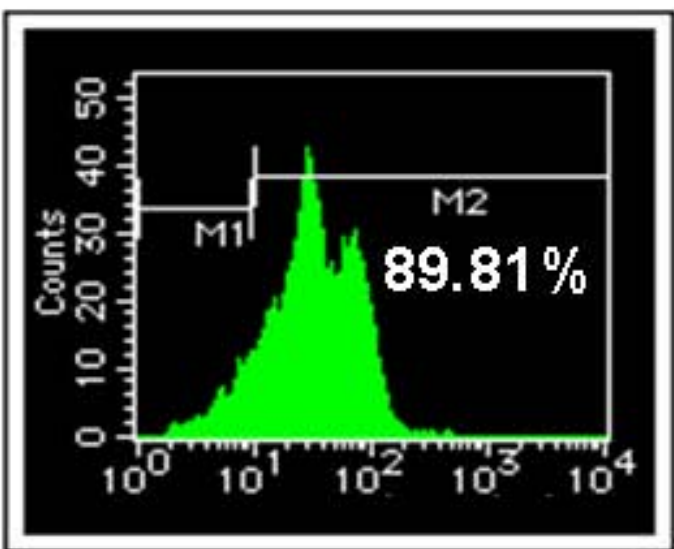


Fig. 5 B

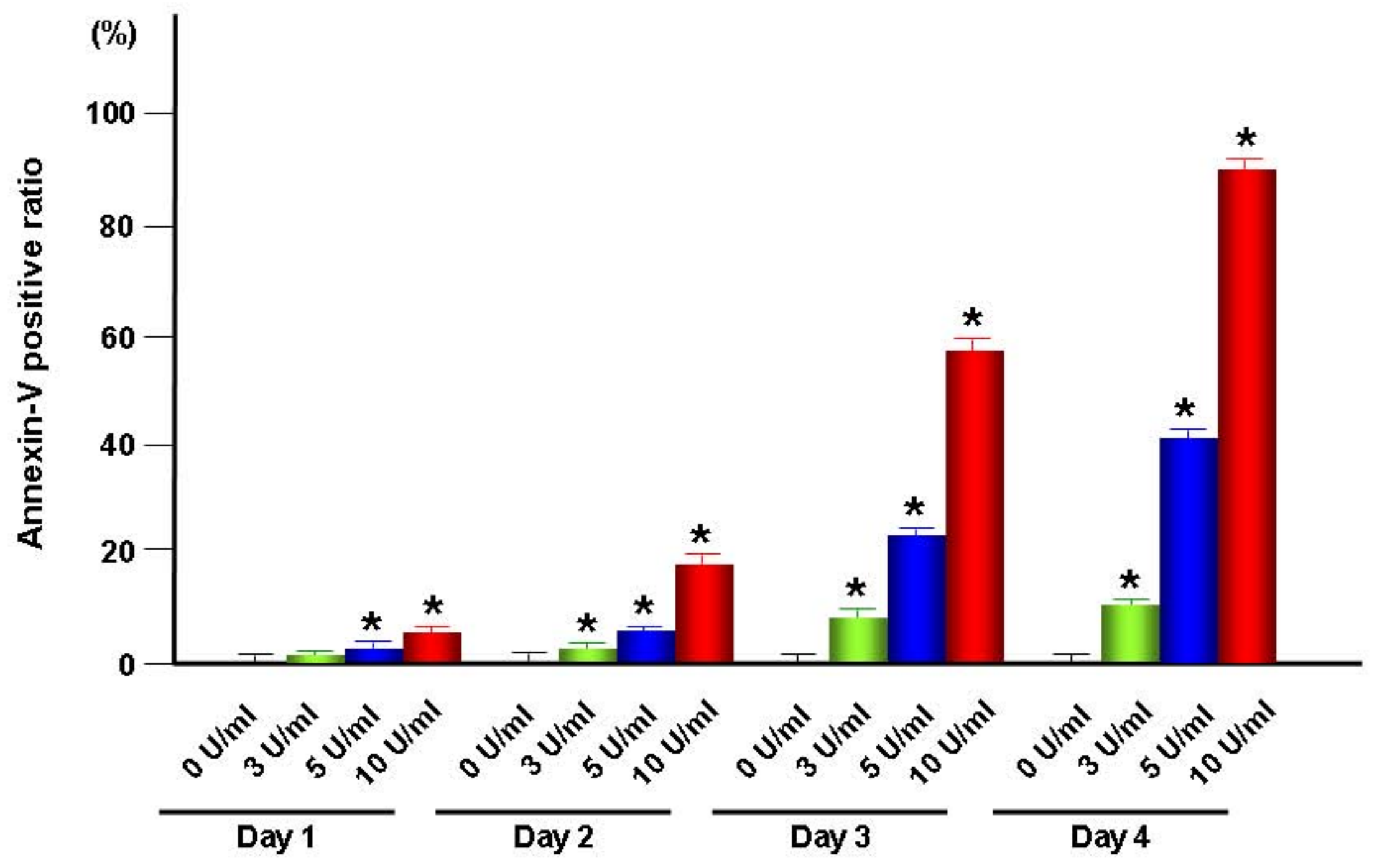

